\title{
Havalı Tüfekle Kaza Sonucu Ölüm: Olgu Sunumu
}

\author{
Accidental Death by Air Rifle: A Case Report \\ Alper Keten ${ }^{1}$, Abdullah Avşar ${ }^{2}$, Ramazan Karanfil ${ }^{2}$, Erdem Okdemir ${ }^{1}$
}

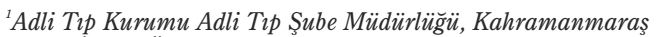

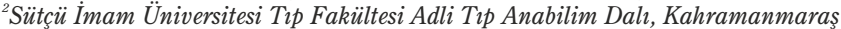

\begin{abstract}
Özet
Havalı silahlar ateşli silahlara göre kinetik enerjileri ve yaralama kapasiteleri daha düşük silahlardır. Buna rağmen özellikle çocuklarda mortalite ve morbidite nedeni olabilirler. Özellikle yakın mesafeden yapılan atışlarda iç organ yaralanması yapmaları mümkündür. Olgumuz 6 yaşında erkek çocuk olup havalı tüfekle yaralanmış ve göğuis boşluğuna giren saçma tanesi akciğer ve aortada yaralanma yaparak cilt altında kalmıştır. Çocuk kan kaybı nedeniyle ölmüştür. Birçok ülkede bu silahların namlu çıkış enerjileri, sahip olma, kullanım ve üretiminde sınırlar bulunmakla birlikte ülkemizde bu konuda sınırlama bulunmamaktadır. Çalışmada bu silahla olan yaralanmaların nası önlenebileceği uluslar arası uygulamalar ve literatür ile birlikte tartışlacaktır.
\end{abstract}

Anahtar Kelimeler: Havalı tüfek, Ölüm, Otopsi.

\section{Giriş}

Havalı silahlar ülkemizde spor ve hobi amaçlı üretimine ve satışına izin verilen çoğunlukla düşük kinetik enerjili, morbitidesi nadir olmamakla birlikte nadiren mortalite nedeni olan silahlardır (1). Bu çalışmada havalı tüfek saçma yaralanmasına bağlı bir ölüm olgusu sunulmuş ve yasal ve teknik düzenlemelerle bu tip silahla yaralanmaların önlenebilmesi hususu literatür eşliğinde tartışılmıştır.

\section{Olgu Sunumu}

Altı yaşında erkek çocuk piknik yaptıkları sırada 5 yaşında başka bir çocuk tarafından tek saçma yaralanması gerçekleşmiştir. Yaralanma sonrasında hastaneye götürülmüsş. Hastanede müdahale yapilamadan eksitus olarak kabul edilmiştir.

Otopsi işleminde dış muayenede Göğüs solda meme başından $9 \mathrm{~cm}$ yukarıda $3 \mathrm{~cm}$ dış kısımda etrafı ekimozlu 0.5 cm'lik saçma giriş deliği tespit edildi. Başka travmatik lezyona rastlanmadı. İç muayende; göğüs solda yaralanma bölgesinin altında $5 \mathrm{~cm}$ çapında hematom tespit edildi. Saçma tanesinin 4-5 kot aralığından göğüs boşluğuna girdiği görüldü. Saçma

\footnotetext{
Sorumlu Yazar: Erdem Okdemir

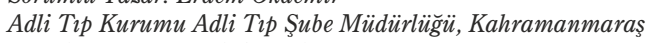

E-mail: erdemokdemir@gmail.com
}

\section{Abstract}

Wounding potential and kinetic energy of airguns are less than firearms'. However, air guns may cause mortality and morbidity especially in children. They can cause fatal internal organ injuries from close range shots. Our case, a 6 year-old boy was injured by air rifle, the pellet entered the chest cavity and injured lung and aorta causing him to die as a result of bleeding. Studies showed some countries have limits on muzzle energy, ownership, utilization and manufacture of airguns contrary to Turkey. In this study, we discussed preventing injuries caused by air rifle through international practice and literature.

Keywords: Air Rifle, Death, Autopsy.

tanesinin sol akciğer alt lobdan girdiği aort kökünü rüptüre ederek sağ akciğer alt lobu geçtiği ve göğüs kafesi sağda 7-8 kot arasından cilt altına ulaştığ tespit edildi. Cilt altından bir adet havalı tüfek saçma tanesi çıkarıldı. Göğüs boşluğunda 1300 cc kan boşaltıldı. (Resim 1-2)

Otopsi işlemi sonrasında ölümün havalı tüfek saçma tanesi yaralanmasına bağlı iç organ ve büyük damara yaralanması nedeniyle meydana geldiği tespit edildi.

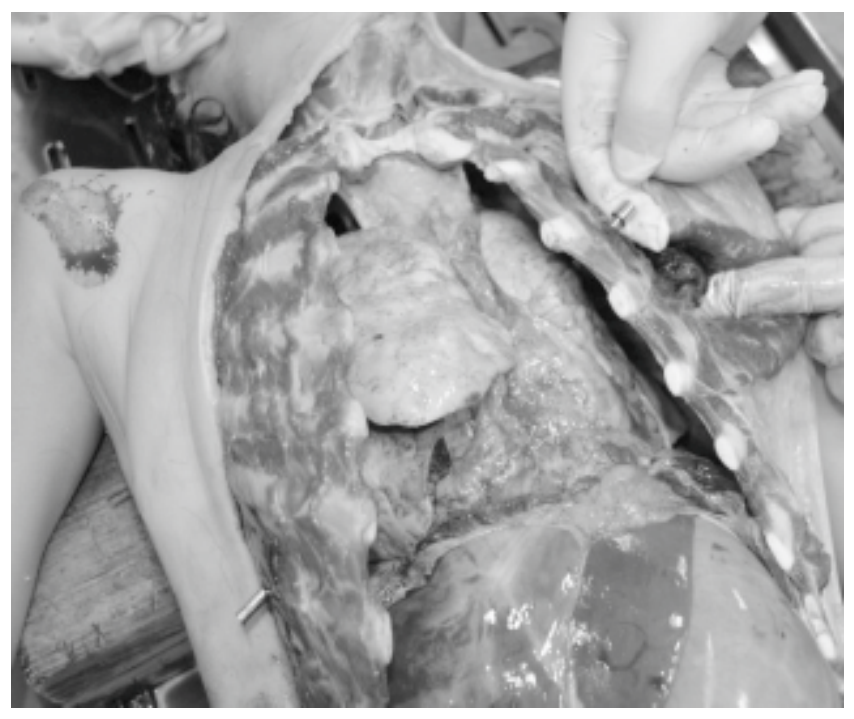

Resim 1. Traje. 


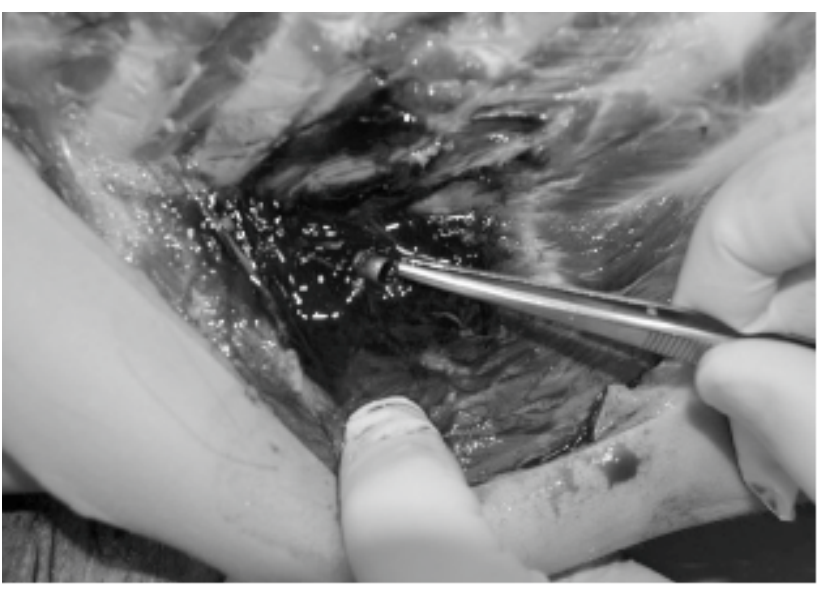

Resim 2. Cilt altından çıkartılan diabol.

\section{Tartışma ve Sonuç}

Havalı silahlar özellikle yakın mesafeden yapılan atışlarda mortalite ve morbiditeye neden olabilmektedir. Temmuz 1994 öncesi 5 yıllık periyotta ABD'de 33 havalı silahla ölüm vakası bildirilmiștir (2,3). Bununla birlikte ABD'de 1999 yıll içerisinde kayıtlara geçmiş 18911 havalı silah yaralanmasının \%76’sı 19 yaş altı kişilerdir (4).

Yapılan çalışmalarda havalı silah yaralanmalarının vücuttaki dağılımında gözün ilk sırada yer aldığı, sıklık sırasıyla alt ekstremite, göz dışındaki baş bölgeleri, üst ekstremite, toraks, boyun ve karnın yer aldığ 1 görülmüştür (1,5-8). Ülkemizde 1992-93 Temmuz döneminde yapılan bir çalışmada Adli Tıp Kurumu Başkanlığına gelen 11 olgudan 5’inin göz yaralanması olduğu görülmüştür (9).

Havalı tüfek saçma yaralanmasına bağlı ölümlerde sıklıkla iç organ yaralanması meydana geldiği görülmüsştür. Yapılan bir çalışmada havalı silahlarla meydana gelen 5 ölüm vakasından 3 'ünde atışların kafaya isabet ettiği, 2'sinde göğse isabet ettiği ve göğse isabet eden iki atıştan birinin sol ventrikül seyirli olduğu diğerinin ise perikardı delerek çıkan aortada yırtık oluşturduğu belirtilmiştir (10). Bizim olgumuzda da saçma tanesinin aort ve her iki akciğerde yaralanma oluşturduğu tespit edilmiştir.

Birçok ülkede havalı silahların kullanılması ve üretim özellikleri konusunda düzenlemeler mevcuttur. Havalı silahların satın alma yaşı örneğin Almanya'da 18, kullanma yaşı örneğin 12 (11) iken Fransa'da 9-16 yaş arası çocukların kullanımı velinin yazılı iznine tabidir (12). Bununla birlikte namlu çıkış enerjisi sınırlaması örneğin Kanada için 5,7 J (13) iken Almanya'da 7,5 J üzerindeki havalı silahlar izne tabidir
(11). Hırvatistan'da da 2012 yılında çıkan bir yasayla namlu ucu kinetik enerjisi 10,5 J ve namlu çıkış hızı $200 \mathrm{~m} / \mathrm{sn}$ ile kalibre ise 4,5 mm ile sınırlandırılmıştır (14). Ülkemizde bu konularda standart bulunmamaktadır.

Yaralanmaların oluşmasında Saçma/Diaboldeki metal oranı ve saçma tanesinin şekli önem taşımaktadır (12). Metal oranı saçma tanesinin deliciliğini etkilemektedir. Ülkemizde bu konuda da standart düzenleme bulunmamaktadır.

Sonuç olarak havalı silahlarla medyana gelen yaralanmalar ölümle sonuçlanabilmektedir. Yaralanma ve ölüm olgularının önlenebilmesi amacıyla gerekli koruyucu tedbirlerin alınması önem taşımaktadır. Bu amaçla; silah edinme yaşı ve kullanma yetkisi yasalarla düzenlenmeli, saçma tanesi metal oranı, çapı ve şekli için bir standart oluşturulmalıdır. Belirli kinetik enerji üzerindeki havalı silahlara lisansla sahip olunmalı ve kullanımı konusunda gerekli eğitim faaliyetleri düzenlenmelidir.

\section{Kaynaklar}

1. Bratton SL, Dowd MD, Brogan TV, Hegenbarth MA. Serious and fatal air gun injuries: more than meets the eye. Pediatrics, 1997; 100(4): 609-612.

2. Naude GP, Bongard FS.Form deadly weapon to toy and back again: the danger of air rifles. Journal of Trauma-Injury, Infection and Critical Care. 1996; 41(6): 1038-1043.

3. Bond SJ, Schnier GC, Miller FB. Air-powered guns: too much firepowerto be a toy Journal of Trauma-Injury, Infection and Critical Care 1996; 41(4): 674-678.

4. Nguyen MH, Annest JL, Mercy JA, Fingerhut LA. Trends in $\mathrm{BB} /$ pellet gun injuries in children and teenagers in United States, 1985-99. İnjury Prevention. 2002; 8: 185-191.

5. Bowen DI, Magauran DM. Ocular Injuries Caused by Airgun Pellets. British Medical Journal. 1973; 1:333-337.

6. Langley DJ, Norton NR, Alsop JC, Marshall SW. Airgun Injuries in New Zealand 1979-92. Injury Prevention. 1996; 2:114-117.

7. Scribano PPV, Nance M, Reilly P, Sing RF, Selbst SM. Pediatric Nonpowder Firearm Injuries: Outcomes in an Urban Pediatric Setting. Pediatrics. 1997;100(4)e5-e5.

8. Abad S, McHenry D1, Carter LM, Mitchell D. Carotid Artery Injury from an Airgun Pellet: A case report and review of the literature. Head Face Medical. 2009; 5:13-18.

9. Kırangil B, Yavuz F, Sarı H, Eriş S, Günay Y, Üner B.Havalı silah yaralanmaları. 7. Ulusal Adli Tıp Günleri 1-5 Kasım. Antalya. 1993; 69-76.

10. Milroy CM, Clark JC, Carter N, Rutty G, Rooney N.Air Weapon Fatalities. J.Clin. Pathol, 1998;51:525-529.

11. http://www.gesetze-im-internet.de/bundesrecht/waffg_ 2002/gesamt.pdf. (Erișim Tarihi: 20.10.2014

12. Öğünç Gİ. Havalı Silah Yaralanmaları ve Hukuki Sonuçları. Ankara Üniversitesi Disiplinlerarası Adli Tıp Anabilim Dalı Doktora Tezi. Ankara . 2010:70

13. http://www.rcmp-grc.gc.ca/cfp-pcaf/fs-fd/air_gun-arme_aireng.htm. (Erişim Tarihi: 20.10.2014)

14. Bakovic M, Petrovecki V, Strinovic D, Mayer D. HYPERLINK "http://www.ncbi.nlm.nih.gov/pubmed/24846815" Shot through the heart-firepower and potential lethality of air weapons. J Forensic Sci. 2014 Nov;59(6):1658-61. 